\title{
Prevalence of Tracheoesophageal Anomaly Cases among Neonates Undergoing Surgery in a Tertiary Care Children's Hospital
}

\author{
Bal Mukunda Basnet, 'Prashant Simkhada, 'Anupama Thapa Basnet,' Raj Kumar Singh' \\ 'Department of Surgery, Kanti Children's Hospital, Maharajguni, Kathmandu, Nepal.
}

\section{ABSTRACT}

Introduction: Tracheo-oesophageal anomaly is the abnormal communication between trachea and oesophagus. The most common type of tracheo-oesophageal anomaly is oesophageal atreasia with distal tracheo oesophageal fistula. Tracheo-oesophageal anomaly is a common neonatal problem requiring an urgent surgery. Tracheo-oesophageal anomaly can be diagnosed as an isolated malformation or as part of polymalformative syndrome with possible vertebrae anomalies also known as Vacterl syndrome. The aim of the study is to find out the prevalence of tracheo-oesophageal anomaly cases among neonates undergoing surgery in a tertiary care childrens hospital in Nepal.

Methods: This is a descriptive cross sectional study conducted in a tertiary care children's hospital in Nepal taking into account the medical records from period of 01 Jan, 2018 to Dec 31, 2019. Study population included the infants undergoing operative procedure in the operation theatre of Kanti Children's Hospital. The calculated sample size was 306. Data was collected by retrospective chart review technique and listed in performa. Consecutive sampling technique was used. Thus collected data was entered in SPSS version 20 and necessary calculations were done.

Results: The prevalence of tracheo-oesophageal anomalies was found out to be $30(9.8 \%)$ at $95 \%$ confidence interval. The most common problem, with which infants were brought to Kanti Children's Hospital, that required urgent neonatal surgical intervention was anorectal malformation constituting $94(30.72 \%)$ of the surgeries followed by intestinal obstruction $76(24.84 \%)$ which included duodenal atresia, jujunal atresia and ileal atresia.

Conclusions: Tracheo-oesophageal anomaly constitutes a major portion of neonatal disease condition requiring surgery in Nepal.

Keywords: neonates; Nepal; tracheo-oesophageal anomalies.

\section{INTRODUCTION}

Tracheo-oesophageal fistula (TOF) is the abnormal communication between trachea and oesophagus. ${ }^{1}$ Esophageal atresia (EA) is the most common congenital anomaly of the esophagus characterized by the complete discontinuity of the esophagus with or without an abnormal connection between the esophagus and the trachea. ${ }^{2-4}$ The survival rate is over $95 \% .^{5}$
EA-TOF can be diagnosed as an isolated malformation or as part of polymalformative syndrome with possible vertebrae anomalies (VACTERL syndrome). ${ }^{6}$ EA-TOF patients bear a higher risk of scoliosis during their

Correspondence: Dr. Prashant Simkhada, Department of Surgery, Kanti Children's Hospital, Maharajguni, Kathmandu, Nepal, Email: dr.prashantsimkhada@gmail.com, Phone: +977. 9843405476 . 
lifetime..$^{7-9}$ Operative techniques for the initial EA-TOF repair as well as the presence of vertebral malformation are two potential pathogenic mechanisms leading to development of scoliosis. ${ }^{10-12}$ The major causes of neonatal deaths are birth asphyxia, prematurity and severe infections. ${ }^{13-14}$ Surgical conditions remains as a major cause of neonatal admission to hospital. ${ }^{15}$

We attempt to find out the prevalence of teacheooesophageal anomaly cases among neonates undergoing surgery in Kanti Children's Hospital.

\section{METHODS}

This is a descriptive cross sectional study conducted in a tertiary care children's hospital in Nepal taking into account the medical records from period of 01 Jan, 2018 to $31 \mathrm{Dec}, 2019$. The ethical approval was taken from the Institutional Review Committee of Kanti children's Hopsital (Ref: 633). Study population included the infants undergoing major operative procedure in the operation theatre of Kanti Children's Hospital. The calculated sample size should be 306 . The sample size was calculated as follows:

$\mathrm{n}=\mathrm{z} 2 \mathrm{pq} / \mathrm{e} 2$

$$
\begin{aligned}
& =(1.96) 2 \times 0.1 \times 0.9 /(0.05) \\
& =3.84 \times 0.09 / 0.0025 \\
& =139
\end{aligned}
$$

For consecutive sampling technique used, Sample size is doubled: $2 \times n 1$

$$
\begin{aligned}
& =2 \times 139 \\
& =278
\end{aligned}
$$

Considering $10 \%$ missing records:

$$
278+10 \% \times 278
$$$$
=306
$$

Data was collected by retrospective chart review technique and listed in performa. Thus collected data was entered in SPSS version 20 and the descriptive statistical calculations were done.

\section{RESULTS}

The prevalence of tracheo-oesophageal anomaly was found out to be $30(9.8 \%)$ at confidence interval of $95 \%$. The most common problem, with which infants were brought to Kanti Children's Hospital and required urgent neonatal surgical intervention was anorectal malformation constituting 94 (30.72\%) of the surgeries followed by intestinal obstruction 76 (24.84\%) which included duodenal atresia, jejunal atresia and ileal atresia. The frequency and percentage of various neonatal surgical procedures taking place in the Kanti Children's Hospital is shown (Figure 1).

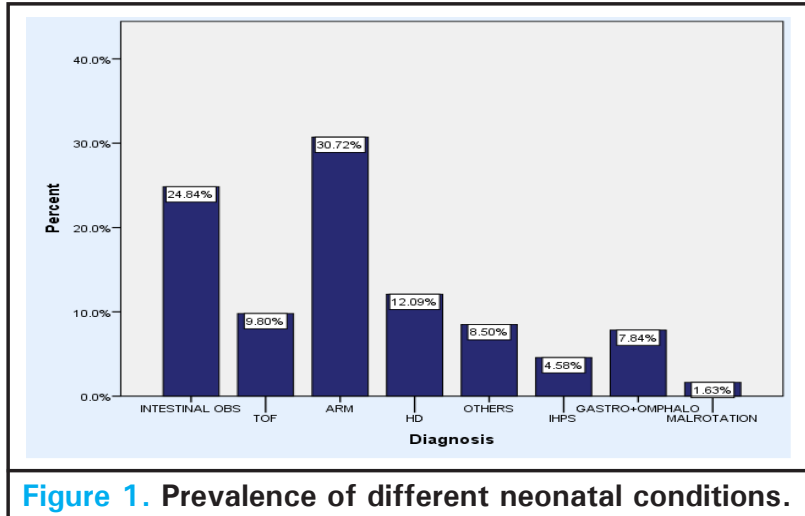

Among those undergoing surgery, 235(76.8\%) were male and $71(23.2 \%)$ were females (Figure2).

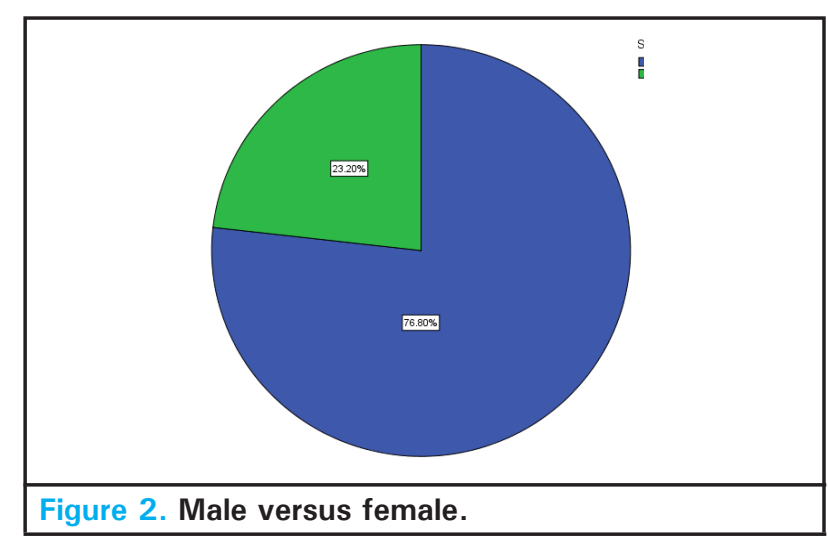

Maximum of the neonates were brought to hospital by $3^{\text {rd }}$ day of life ( Figure 3).

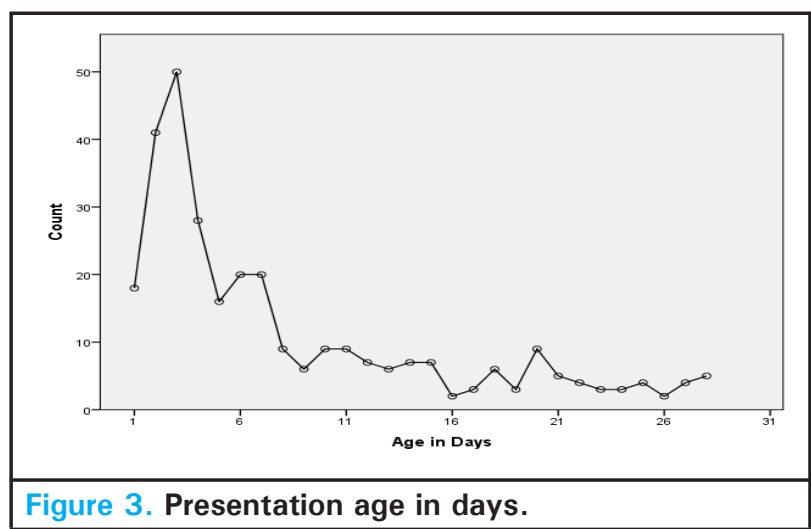

Male to female ratio for individual disease was highest for ARM (Figure 4). 


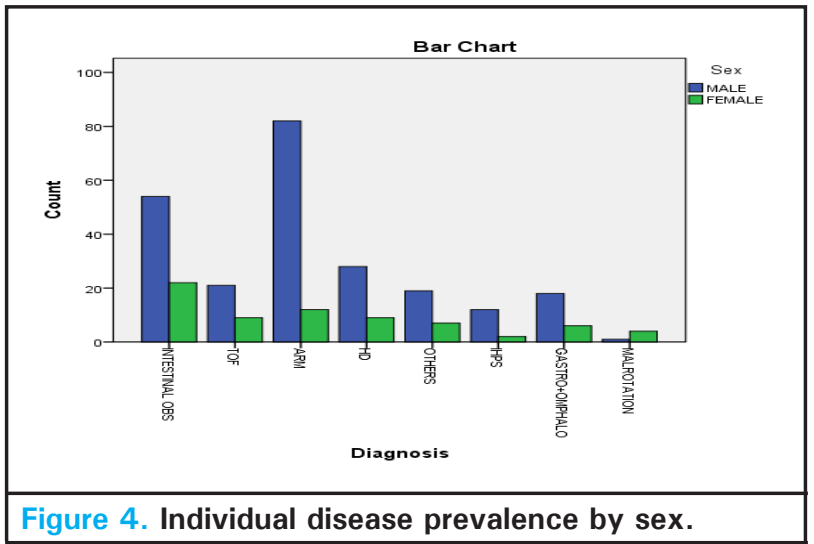

\section{DISCUSSION}

The prevalence of tracheo-oesophageal anomalies among neonates undergoing surgery in a tertiary care childrens hospital in Nepal was found out to be 30 (9.8\%).

Among those undergoing surgery 235 (76.8\%) were male and 71 (23.2\%) were female. In a study by AbdulMumin A et al in Ghana, including 347 infants admitted to the NICU with neonatal surgical conditions, the number of male patients was $177(52 \%)$ and female was 165 (48\%). ${ }^{16}$ In a study done by Bastola R et al in Western Regional Hospital Nepal, the prevalence of congenital birth defect was found to be more in males. ${ }^{17}$

In their study, among the 1144 total admissions with congenital anoamaly 54.1 percentage of the patients were male which is lower compared to the percentage of males undergoing surgery in Kanti childrens Hospital, it is still higher compared to females presenting to their center. ${ }^{17}$

The most common problem was anorectal malformation followed by intestinal obstruction, Hirschprung's Disease, TOF and so on (Figure 1). In the study by Bastola $R$ et al in Western Regional Hospital
Nepal, maximun number of patient were admitted with congenital syndromes ( Downs, Pirre Robins, Goldhenar's or Arthrogryposis multiplex congenita) followed by eye, ear, face and neck conditions followed by gastrointestinal malformations. In our study, gastrointestinal anomalies lead the table of causes of neonatal surgical procedure. This might be because of the surgical facility available at our set up and being a referral center from throughout the country. Similarly in the study by Abdul-Mumin A et al in Ghana, the most common anomalies were omphalocele 48 (13.8\%), imperforate anus 34 (9.8\%), intestinal obstruction 29 $(8.4 \%)$, spina bifida $26(7.5 \%)$ and hydrocephalus 19 $(5.5 \%){ }^{16}$

Maximum of the neonates were brought to hospital by $3^{\text {rd }}$ day of life. $193(63.1 \%)$ of the neonates were less than 7 days by age.

The actual burden of the teacheo-oesophageal anomalies among the neonates of Nepal was unknown. In this study, we made an attempt to know the approximate of the condition in Nepal and also know the pattern of neonatal surgery in a tertiary care center in Nepal. For consecutive sampling technique sample size is doubled and sample size is adjusted considering $10 \%$ of missing records which avoids the selection bias, however being a single centered study it lacks the external validity.

\section{CONCLUSIONS}

Tracheo- oesophageal anomaly constitutes a major part of neonatal disease condition requiring surgery in Nepal.

\section{ACKNOWLEDGEMENTS}

I would like to thank all the staffs in the operation theatre and the records section of Kanti Children's Hospital for their cooperation during data collection.

\section{Conflict of Interest: None.}

\section{REFERENCES}

1. Salgaonkar HP, Sharma PC, Chhakarvarty N, Ramadwar R, Mehta R, Bhandarkar DS. Thoracoscopic repair of congenital tracheo-oesophageal fistula manifesting in an adult. J Minim Access Surg. 2014 Oct;10(4):204-6. [PubMed I Full Text [DOI]

2. Spitz L. Oesophageal atresia. Orphanet journal of rare diseases. 2007;2:24. [Full Text]
3. Teague WJ, Karpelowsky J. Surgical management of oesophageal atresia. Paediatr Respir Rev. 2016;19:10-5. [PubMed | Full Text | DOI]

4. Smith N. Oesophageal atresia and tracheo-oesophageal fistula. Early Hum Dev. 2014;90(12):947-50. [PubMed | Full $\underline{\text { Text }} \mid \underline{\text { DOI] }}$ 
5. Sistonen SJ, Pakarinen MP, Rintala RJ. Long-term results of esophageal atresia: Helsinki experience and review of literature. Pediatr Surg Int. 2011;27(11):1141-9. [PubMed | Full Text $\mid \underline{\text { DOI] }}$

6. Keckler SJ, St Peter SD, Valusek PA, Tsao K, Snyder CL, Holcomb GW, 3rd, et al. VACTERL anomalies in patients with esophageal atresia: an updated delineation of the spectrum and review of the literature. Pediatr Surg Int. 2007;23(4):309-13. [PubMed | Full Text | DOI]

7. Durning RP, Scoles PV, Fox OD. Scoliosis after thoracotomy in tracheoesophageal fistula patients. A follow-up study. J Bone Joint Surg Am. 1980;62(7):1156-9. [PubMed | Full Text | DOI]

8. Gilsanz V, Boechat IM, Birnberg FA, King JD. Scoliosis after thoracotomy for esophageal atresia. AJR Am J Roentgenol. 1983;141(3):457-60. [PubMed | Full Text | DOI]

9. Westfelt JN, Nordwall A. Thoracotomy and scoliosis. Spine.

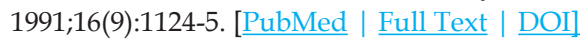

10. Roclawski M, Sabiniewicz R, Potaz P, Smoczynski A, Pankowski R, Mazurek T, et al. Scoliosis in patients with aortic coarctation and patent ductus arteriosus: does standard posterolateral thoracotomy play a role in the development of the lateral curve of the spine? Pediatr

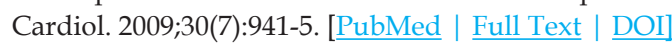

11. Roclawski M, Pankowski R, Smoczynski A, Ceynowa M, Kloc W, Wasilewski W, et al. Secondary scoliosis after thoracotomy in patients with aortic coarctation and patent ductus arteriosus. Stud Health Technol Inform. 2012;176:43-6. [PubMed | Full Text]
12. Korovessis P, Papanastasiou D, Dimas A, Karayannis A. Scoliosis by acquired rib fusion after thoracotomy in infancy. European spine journal: official publication of the European Spine Society, the European Spinal Deformity Society, and the European Section of the Cervical Spine Research Society. 1993;2(1):53-5. [Full Text]

13. Ugwu RO, Eneh AU. Mortality in the special care baby unit of University of Port Harcourt Teaching Hospital, Port Harcourt, Nigeria: Why and when do newborns die? Niger J Paediatr. 2008;35:75-81. [Full Text]

14. Tinker A, Parker R, Lord D, Greara K. Advancing newborn health: The Saving Newborn Lives initiative. Glob Public Health. 2010 Jan; 5(1): 28-47. [PubMed | DOI]

15. Ugwu RO, Okoro PE. Pattern, outcome and challenges of neonatal surgical cases in a tertiary teaching hospital. Afr J Paediatr Surg. 2013 Jul-Sep;10(3):226-30. [PubMed | Full $\underline{\text { Text }}$ | DOI]

16. Abdul-Mumin A, Anyomih TTK, Owusu SA, Wright N, Decker J, Niemeier Ket all. Burden of Neonatal Surgical Conditions in Northern Ghana. World J Surg. 2020 Jan;44(1):3-11. [ PubMed | Full Text | DOI]

17. Bastola R, Gurung R, Bastola BS, Bastola SS and Bastola L. Pattern and Prevalence of Congenital Birth Defect Among Neonates Admitted to Special Newborn Care Unit (SNCU) Of Pokhara Academy of Health Science (PAHS), Nepal. Journal of Biology and Medical Research. 2018 Jan;2(1):1. [Full Text] 